\title{
Entre pessoas e processos: observações sobre uma agência de publicidade digital
}

\author{
Maria Cristina Dias Alves
}

Universidade de São Paulo, Escola de Comunicações e Artes, São Paulo, Brasil ORCID: https://orcid.org/0000-0001-9790-6068

\begin{abstract}
Resumo
O trabalho das agências de publicidade tem se transformado nos últimos anos, do modelo de negócio aos fluxos e procedimentos. Observei algumas dessas alterações em uma pesquisa de cunho etnográfico em três modelos de agências brasileiras: tradicional, digital e colaborativa. Especificamente neste texto, apresento um recorte da pesquisa na agência digital e as principais análises realizadas a partir de um quadro teórico que abarca os conceitos de dispositivo, mediações e midiatização. Durante a pesquisa, foi possível observar a interação em funcionamento, o saber técnico alinhado à mídia, e processos de criação valorizados pela capacidade de dar vida às ideias. Há uma reação das agências para ampliar a prestação de serviços de comunicação por meio da tecnologia, o que requer aproximar sistemas informacionais e inovações técnicas da criação de campanhas. Na agência digital pesquisada, o movimento por interação está na origem, intensificado pelo domínio mais técnico da programação e do comportamento do consumidor, em um mundo cada vez mais dataficado.
\end{abstract}

\section{Palavras-chave}

Agência digital; Dispositivos; Interação; Mediação; Midiatização

\section{Mediações e transformações}

0 trabalho das agências de publicidade tem se transformado nos últimos anos, desde o próprio modelo de negócio, cada vez mais indeterminado, aos fluxos, organogramas e procedimentos. Em minha tese de doutorado me debrucei sobre essas alterações e realizei uma pesquisa de cunho etnográfico em três modelos de agências brasileiras: tradicional, digital e colaborativa ${ }^{1}$. Acompanhei de perto os processos criativos das duplas de criação, além de localizar o papel dos profissionais junto à ação dos dispositivos tecnodiscursivos, no

\footnotetext{
${ }^{1}$ Foram pesquisados três modelos de agências, entre as 20 maiores do país, localizadas no maior mercado nacional, que é a cidade de São Paulo: uma tradicional, originalmente voltada para a mídia off-line; uma digital, com trabalhos para as mídias digitais, redes on-line e projetos de e-commerce e, enfim, uma colaborativa, modelo híbrido de negócio publicitário que congrega várias atividades afins. As agências, clientes e nomes dos profissionais não foram divulgados por acordo de confidencialidade (ALVES, 2016).
} 
que conformam homogeneidades, metodologias e controle. As observações e análises foram realizadas na perspectiva da interação, cuja gramaticalidade fornece categorizações de procedimentos e possibilita distinções nos modelos de negócio, a partir de um quadro teórico que abarca os conceitos de dispositivo (AGAMBEN, 2011; DELEUZE, 1999; FOUCAULT, 2000), mediação (LOPES, 2018; MÁRTIN-BARBERO, 2009) e midiatização nos procedimentos de trabalho, um novo processo interacional de referência (BRAGA, 2009).

Para Braga (2006, p. 30), a midiatização é um movimento que vai das estruturas a processos, de instituições (ou grupos delas) para uma classe de atividades, sistemas processuais e não estruturais, contudo, como escreve o autor, tanto os processos geram estruturas tanto quanto estas se realizam em processos. Nesse sentido, os dispositivos midiáticos são produtos e, ao mesmo tempo, produtores de transformações, implicam a autonomia de emissores e receptores, modificam e distorcem sentidos, bem como a relação espaço-tempo: “[...] os fenômenos midiáticos são uma precondição de sistemas sociais complexos e, por isso, a midiatização possui tanta importância quanto estes". (VERÓN, 2014, p. 14).

Desde a década de 1990, Verón se volta à análise da sociedade em vias de midiatização, muito mais complexa do que as anteriores, devido à institucionalização da mídia e as consequentes mudanças sociais. Para o autor, a midiatização faz parte da continuidade histórica de fenômenos midiáticos e não uma decorrência da modernidade. Consequência, sim, da nossa capacidade de semiose (VERóN, 2014, p. 14). São os dispositivos materiais utilizados, desde o primeiro instrumento criado pela espécie humana, que trazem mudanças a processos e práticas sociais. Em outras palavras, o autor considera a midiatização a partir de uma tradição social-construtivista, como Braga e Fausto Neto.

Já Hjarvard (2012) considera a midiatização um processo macrossocial (tal qual a globalização) instituído por uma lógica da mídia: “[...] modus operandi institucional, estético e tecnológico dos meios, incluindo as maneiras pelas quais eles distribuem recursos materiais e simbólicos e funcionam com a ajuda de regras formais e informais [...]" (HJARVARD, 2012, p. 64, 65), uma tradição institucionalista.

A partir dessa lógica, o autor distingue midiatização direta e indireta, diferenciação que permite compreender modos de interação. Há midiatização direta quando determinadas atividades são transformadas na interação com os meios, como acontece com o uso de aplicativos de videoconferência, a exemplo do Zoom. Ou ainda serviços on-line de bancos e de compras entre outros. Na midiatização indireta são os símbolos e os mecanismos midiáticos que influenciam as atividades, ao criar contextos culturais. Ou ainda, a 
intertextualidade entre meios e instituições (HJARVARD, 2012, p. 67, 68). Como as manifestações do ativismo black lives matter norte-americano veiculadas nos media, por exemplo, que influenciam a apreensão das práticas socioculturais daquele país.

Entretanto, aqui utilizo midiatização como instrumento heurístico para analisar processos, como sugere Braga (2012), não dissociado das mediações comunicativas da cultura de Mártin-Barbero, que há anos sinaliza as transformações culturais a partir de uma visão contrária ao pensamento único que faz da tecnologia "o grande mediador" entre as pessoas e o mundo (LOPES, 2014), numa recusa do sentido instrumental de tecnologia presente nos estudos de comunicação (LOPES, 2018). 0 adensamento da mediação da tecnologia torna-a estrutural para Mártin-Barbero, resultando em novas percepções, novas linguagens e sensibilidades como se referem Pieniz e Cenci (2019).

Também Barros (2012) aponta a proximidade entre ambos, sendo as mediações comunicativas da cultura voltadas às interações sociais que ocorrem pela mídia, basicamente. E a midiatização da cultura, para as práticas sociais decorrentes da lógica da mídia (2012, p. 88). Em síntese:

[...] midiatização é um conceito sensibilizante em torno do qual vários pesquisadores se reuniram, interessados em uma investigação empírica da importância do papel que a mídia desempenha na transformação da cultura e da sociedade [...] Sob esse ponto de vista, o termo midiatização refere-se a um discurso aberto e contínuo de teorização sobre transformações sociais e culturais em relação à mídia e às comunicações. (HEPP, 2020, p. 15, tradução nossa).

Com esse olhar, acompanhei os profissionais das agências no dia a dia de trabalho a fim de investigar a ocorrência de midiatização direta ou indireta. Corri o risco de aproximar mediação e midiatização ao observar e classificar a interação em processos de trabalho: os modos de fazer das duplas de criação compostas por redatores, diretores de arte e, inclusive, programadores ${ }^{2}$, combinados a outras conexões, que, contudo, têm implicadas às anteriores, nem sempre percebidas. 0 excesso de informações fragmentadas na rede on-line acelera processos, permite acesso a tudo por todos e muitos profissionais não se dão conta do caráter plurissígnico da publicidade conformado em procedimentos sistêmicos.

\footnotetext{
2 Utilizo o gênero masculino dada a presença maciça desses profissionais na criação e, principalmente, à confidencialidade exigida na pesquisa. Não se trata de um juízo de valor.
} 


\section{Uma agência digital}

Antes de iniciar as observações, realizei uma pesquisa exploratória sobre formatos e fluxos de trabalho das agências digitais e foi possível discernir dois modelos: as que prestam serviços de comunicação por meio de plataformas digitais, games, aplicativos e peças para a rede on-line; e as que executam serviços de TI (tecnologia da informação), gestão de dados e marketing digital, ainda que essa terminologia não comporte a abrangência dos possíveis serviços prestados. A revisão bibliográfica permitiu compreender os modelos de negócio desse tipo de organização - agência digital -, mas não localizei nenhum estudo conclusivo do campo da comunicação. Essa incerteza decorre das definições do tipo de trabalho que as agências digitais executam, cuja consolidação tem sido alterada devido às empresas de tecnologia, que passaram a oferecer prestação de serviços para as marcas, como ocorreu com a Accenture, que adquiriu a New Content no Brasil, além da Droga 5, de Nova Iorque, uma das agências mais premiadas do mundo (ACCENTURE..., 2019).

Um olhar retrospectivo para esse modelo de agência leva ao fim dos anos de 1990, quando a maioria dos serviços para a internet era realizada por empresas de computação, especializadas em sistemas de automação ou de multimídia, sendo as primeiras peças publicitárias criadas somente em 1994, quando os buscadores (como o Yahoo) começaram a tomar forma e a atrair consumidores que desejavam encontrar os sites das empresas na web ou mesmo realizar compras (PINHO, 2000, p. 192, 193). Um ano depois, muitas empresas passaram a se interessar pela visibilidade proporcionada pela web, como sinal de "modernidade", segundo o autor.

Na agência digital pesquisada há departamentos específicos do universo digital, como os de TI, o de projetos (que pode ou não ser combinado com o de atendimento) e, ainda, outros que se constituem à medida que os processos de trabalho requerem novas competências, tal qual ocorreu no departamento de mídia com a chegada dos profissionais de BI (business intelligence), de performance e os analistas de mídias sociais. Essas denominações trazem normatizações que, por sua vez, remetem ao conceito de dispositivo, localizado num jogo de poder, “[...] as estratégias de relações de força sustentando tipos de saber e sendo sustentadas por eles [...]" (FOUCAULT, 2000, p. 140). 0 poder e o saber seriam uma terceira dimensão no espaço interno do dispositivo, essa "máquina de fazer ver e de fazer falar", segundo Deleuze (1999, p. 156), que o localiza nos regimes de enunciação; do que é visível e do que é enunciável, implicando linhas de força.

0 uso frequente da palavra task na agência digital, ao contrário de job (termo 
utilizado para nomear os pedidos de trabalho de agências de publicidade), constitui um exemplo singular. Ao comparar a definição de ambas as palavras, verifico que task (tarefa) tem um caráter mais prático, refere-se à realização de um trabalho ou empreitada num determinado prazo. Já job (trabalho) traz sinônimos que valorizam o fazer, tanto manual como intelectualmente. Essa pequena distinção de terminologia faz emergir as linhas de visibilidade e de enunciação sobre as quais se refere Deleuze (1999), imanentes em cada dispositivo, e que relaciono ao fazer técnico das agências digitais.

Outro exemplo são os dispositivos de controle, como os relatórios de timesheet para medir o tempo de trabalho dos profissionais na realização das tarefas, por hora-homem ${ }^{3}$. Esses relatórios, também presentes em outros modelos de agência, existem há algum tempo, antes preenchidos no papel e entregues uma vez por mês e, agora, controlados diariamente por sistemas de trabalho informatizados.

Outra característica comum nas agências digitais é a ausência da produção gráfica, departamento que cuida das peças físicas, impressas. Em seu lugar há o de projetos, responsável por todas as produções, inclusive de RTV (rádio e televisão). Nesse departamento são realizados todos os orçamentos de materiais, predominantemente audiovisuais, porque a maioria dos trabalhos - posts, blogs, conteúdos - é produzida internamente.

Há quatro divisões de trabalho na criação desta agência digital, segundo o diretor de criação: as plataformas, que são portais e hubs, ou seja, as estruturas; e a propaganda, como hot sites, campanhas, display, banners e pop ups. E, ainda, social media, app e ferramentas. Para realizar esses trabalhos, a criação é dividida em dois grupos, sendo um de criação (equipe sênior), denominado demandas da propaganda e outro de produção criativa (demais criativos plenos ou juniores).

É comum que a equipe de produção criativa dê andamento a um trabalho já criado, como também observei na agência de modelo tradicional (ALVES, 2016), na qual os assistentes ou equipes de juniores tocam o trabalho idealizado pelos seniores. Algumas peças são criadas pelos redatores seniores e diagramadas por diretores de arte da produção criativa, como os textos para blogs de clientes e posts, devido a um padrão preestabelecido e por ser um trabalho recorrente. Segundo um dos redatores, são quinze posts por mês, em média, para cada cliente, com conteúdo alimentado pelo atendimento/planejamento. Pode

\footnotetext{
3 Os custos por hora-homem constam nas tabelas de preços de serviços fornecidas pelas associações das agências (ASSOCIAÇÃO BRASILEIRA DOS AGENTES DIGITAIS, 2020).
} 
acontecer, ainda, de alguns trabalhos serem feitos pelas duplas seniores, mesmo devolutivas (refações). Isso depende de cada caso e do peso do job, como foi observado no modelo de briefing visualizado, em que há uma valoração do trabalho sinalizada em grau de importância: ouro, quando é de alta importância para o cliente e a criação deve ser mais detalhada, que inclui planejamento; prata, quando são projetos do dia a dia, e bronze, para projetos simples e rápidos.

Apesar da distinção de um trabalho mais técnico, como a criação de sites e até de plataformas de e-commerce, o departamento de criação da agência digital é bastante valorizado, como também acontece na agência de modelo tradicional. Não verifiquei, entretanto, o mesmo encantamento com programadores e profissionais de $\mathrm{TI}$, que na agência tradicional são considerados gênios (ALVES, 2016, p. 80). Na agência digital, esses profissionais ficam em uma sala separada e sob a supervisão do departamento de projetos, uma função mais técnica, talvez pela origem da agência, 100\% digital. Por outro lado, há relevância do departamento de mídia, responsável pelas estratégias que acompanham os movimentos dos consumidores na rede on-line. Conforme o relato informal do diretor de criação, "ele é o cara", aquele que sabe das coisas e cuja importância é asseverada pelo próprio responsável do departamento:

[...] normalmente a gente tem um briefing, sim, esse briefing ... eu penso que a mídia consegue e deve fazer interface com todos os momentos desse briefing. Então, a criação deve sim considerar a mídia na sua tomada de decisão criativa, porque, dependendo, pode ser totalmente viável ou inviável o que eles estão começando a pensar. E quem vai, talvez, viabilizar isso ou dizer que é viável é o mídia. Por exemplo, você está indo por um caminho...você quer que o usuário faça o download disso? Por que você faria o download disso? Então, o pensamento da mídia deve ajudar a influenciar toda a criação e, inclusive, o resultado, o negócio. (DIRETOR DE MÍDIA, agência digital).

Mesmo se referindo ao profissional de mídia com entusiasmo, o diretor de criação acentua a valorização do seu departamento e, quando confrontado sobre a posição do planejamento e das demais áreas, considera que a criação faz toda a diferença, responsável pela magia, a ideia, que deflagra todos os demais processos. 


\section{Um processo criativo}

Além das entrevistas realizadas ${ }^{4}$, a escolha pela observação participante em todas as agências possibilitou seguir de perto alguns processos de criação e estar presente em reuniões de briefing e de brainstorming, uma vez que o investigador "[...] acompanha e vive (com maior ou menor intensidade) a situação concreta que abriga o objeto de sua investigação. [...] Seu papel é de observador." (PERUZZO, 2003, p.11). A minha experiência em agências (por ser redatora e diretora de criação) permitiu participar, inclusive, de um dos trabalhos, distribuídos a todos os redatores num esforço conjunto para resolver um problema de criação de nomes para um novo aplicativo de um banco.

Descrevo aqui o processo de criação de uma landing page para portadores de cartão de crédito dessa mesma instituição, que propunha a transferência de pontos para o programa de milhagem de uma companhia aérea parceira e, desse modo, possibilitava o up grade no cartão de fidelidade da companhia. 0 diretor de arte selecionou algumas referências de imagens, que buscou na internet, e junto do redator traçaram um caminho criativo bastante gráfico, que deu início ao rascunho da peça. Nesse fazer da dupla, observo um caso de midiatização direta, desde a pesquisa de referências na rede, intercalando a todo o momento o processo criativo; e indireta, pela maneira pela qual discutiam o trabalho, fazendo emergir a materialidade discursiva das representações culturais, tanto do produto, quanto do target: "Formas diretas e indiretas de midiatização muitas vezes operam em combinação, de modo que nem sempre é fácil distingui-las." (HJARVARD, 2012, p. 67), como descrevo a seguir.

0 diretor de arte rascunhou em um papel algo que considerava representar visualmente o up grade de pontos. Associou-o a pequenos círculos, muitas bolinhas, que juntas formavam um avião, para que o correntista pudesse interagir com a imagem: assim que passasse o mouse sobre as bolinhas poderia arrastar a imagem, transformando-a em um avião completo. A solicitação de que o cliente interagisse com a peça foi sugestão do próprio diretor de arte e não do cliente, o que exigiu um trabalho a mais. Nesse caso, o diretor de arte aproveitou as possibilidades da plataforma tendo em vista chamar a atenção do correntista de uma maneira mais lúdica, sedutora e convidativa. Já o texto da landing page (não revelado devido ao acordo de confidencialidade) era simples e informativo, referia-se apenas à troca da milhagem. Isso porque, segundo o redator, era voltado a um cliente

\footnotetext{
4 Considerando todo o corpus, realizei vinte e cinco entrevistas (gravadas em áudio) com trinta profissionais: criação, atendimento, planejamento, mídia, produção, programação, projetos e relações públicas.
} 
especial, de maior poder aquisitivo/faixa etária e requeria certa seriedade.

A mensagem da peça só se revela com a ação do consumidor, ou seja, além da associação por semelhança - bolinhas = pontos -, a interação propõe outra associação, por causa e efeito - movimento = avião -, remetendo à ação do consumidor de trocar seus pontos para realizar uma viagem. Esse tipo de estratégia suasória já ocorria nos anúncios do início do século passado, cuja mensagem se completava a partir da ação do consumidor, como o da Casa Mangueira, que convida o leitor a encostar o nariz na linha para ver o chapéu sobre a cabeça do personagem (figura 1), um elemento de persuasão a mais (CARRASCOZA, 1999 , p. 166, 167). A mudança, na contemporaneidade, recai sobre o suporte e o modo de abordar o consumidor, um caso de midiatização que, como escreve Verón (2014), torna os processos mais acelerados e complexos.

Figura 1 - Anúncio da revista Careta, RJ, de 1908

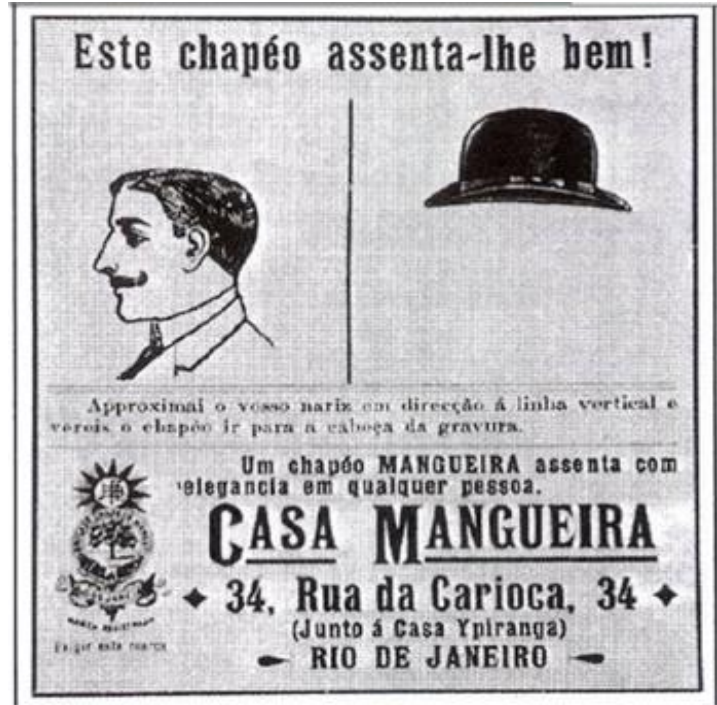

Fonte: Carrascoza (1999, p. 166).

Questionei se esse processo de criação se repetia sempre, o redator disse que considera antes o tipo de trabalho e prazo, como ocorreu nesse caso: tinham apenas três horas para criar a peça e, então, focou somente no que precisava informar. Entretanto, devido à animação proposta, o layout exigiu mais tempo e o trabalho ficou pronto apenas no fim do dia seguinte. Para conseguir adiar o trabalho, antes de realizar a peça, a dupla chamou o atendimento para ver o rascunho e, como concordou com o caminho, conseguiu mais prazo com o cliente.

Como pude observar em outros trabalhos, a escolha dos criativos, de priorizar uma direção de arte fun e interativa e o texto verbal mais informativo, tem sido comum nessa 
agência. Em sua maioria, como e-mails, banners e posts, uma boa ideia conta, mas também a estratégia para atingir o público certo e trabalhar a informação da melhor maneira: "É a busca da organização perfeita daquela informação [...] Ou mais bonito, ou mais inteligente, ou mais rápido, conforme o briefing, conforme o pedido. É o trabalho de tratar a informação, mais do que produzir uma comunicação nova sobre esta informação." (DIRETOR DE CRIAÇÃO [redator], agência digital). A interação é pressuposta, principalmente, quando são peças digitais impulsionadas para um target específico, como os clientes da instituição financeira e, desse modo, a participação do consumidor já é esperada.

O diretor de criação considera o trabalho de criação publicitária mais "artífice do que artístico", como também se refere Washington Olivetto (CARRASCOZA, 2003), e afirma que a chegada das novas tecnologias não mudou esse processo, mas, sim, a maneira de compartilhar o trabalho, armazená-lo e alterá-lo, criando uma falsa ideia de que tudo pode ser mexido por todos e não, necessariamente, pelo profissional criativo, como apontado em um dos trechos da entrevista.

Pergunta: Sim, você acha que mudou só o suporte?

Resposta: Acho que sim [...] os processos criativos são basicamente os mesmos. Acontece que.... as coisas eram mais manufaturadas, então, saiam peças únicas, nem se guardava, mandava aquilo para o cliente e nunca mais via aquela peça... então tinha um carinho especial, achando que era uma peça artística. Ah, a ilustração ficou muito legal, a letra ficou perfeita, parece uma coisa mais arte do que aquilo, que é uma coisa que está dentro do computador de todo mundo... que todo mundo pode trocar, mexer [...] (DIRETOR DE CRIAÇÃO [redator], agência digital).

Nesse sentido, os dispositivos técnicos conformam ausência de controle não apenas na circulação (FAUSTO NETO, 2010), expectativa da lógica produtiva da emissão, mas que se dá antes, na própria agência, no percurso da enunciação publicitária (TRINDADE, 2007), especificamente, no momento de aprovação dos trabalhos. 0 fato de que "todo mundo pode trocar, mexer" resulta em um esgarçamento das fronteiras também entre a agência e o cliente. Os dispositivos técnicos tornam evidentes os limites do poder, que só pode ser capturado por outro dispositivo e, desta feita, um novo saber, que parece ser dominado pelas agências digitais.

[...] quando lá, em 1960, no Mad Men, a agência tinha o cliente na mão por deter todo conhecimento, hoje, eu acho que o digital assume um pouco esse papel, e esse papel eu não sei se ele a curto prazo consegue se soltar, porque, de novo, é muito rápido. As coisas acontecem todos os dias. Por isso, também é importante, e eu acho que também pode ajudar, o planejamento pode 
ajudar com isso, a trazer todas essas referências e coisas novas, porque todo dia tem coisa nova, todo santo dia aparece uma nova forma de mídia, uma nova forma de interação, um novo formato [...] (PLANEJAMENTO JR., agência digital).

A valorização do trabalho criativo é percebida na agência digital, tanto por parte do presidente, como pelos demais departamentos. 0 atendimento salienta a importância do texto verbal, que considera essencial em uma ideia. Já o planejamento refere-se a um trabalho conjunto, no qual apresenta insights para as equipes de criação, que são o início das grandes ideias. Existem ainda os casos de retroplanejamento, quando o processo começa na criação (que recebe a solicitação do briefing juntamente com os demais departamentos), e realiza toda a campanha antes, então, o planejamento faz o caminho inverso, elabora a defesa para validar o conceito e as ideias da campanha, como também observei na agência tradicional (ALVES, 2016, p. 99).

Essa valorização da criação decorre da capacidade de gerar ideias, contar histórias e mobilizar consumidores para curtir e compartilhar as narrativas das marcas e estender essa participação para além, já que hoje é possível obter curtidas por meio de robôs, o que tem exigido mais controle: “[...] eu sou redator, eu sei fazer história, sei o poder do storytelling, sei fazer e gosto de fazer. E, na oportunidade, não deixo de fazer coisas como se fosse um filme de propaganda. Mas esse é um dos recursos, não é nem o mais importante." (DIRETOR DE CRIAÇÃO [redator], agência digital).

Os aparatos técnicos permeiam o dia a dia da criação (nessa e nas demais agências pesquisadas), seja na busca de referências, no compartilhamento de ideias ou mediando a feitura do trabalho por meio de diferentes softwares. É a mediação da tecnicidade, não como instrumento, mas própria da estrutura da cognição e do dia a dia, como escreve Lopes (2018a, p. 58) ao se referir à atualização do mapa das mediações de Mártin-Barbero “[...] conduzindo a um forte borramento das fronteiras entre razão e imaginação, saber e informação, arte e ciência, saber especializado e conhecimento comum [...]”.

Nessa agência digital, as equipes se comunicam constantemente via chat e, quando a dupla precisa discutir o trabalho (brainstorming), às vezes o faz na sala mesmo, num bate papo em que redator e diretor de arte rascunham no papel ou trocam referências. Em outras, as equipes se apartam para conversar em um ambiente aberto, que fica no topo da casa, um jardim no mezanino com mesas e cadeiras. Há interação presencial e também mediada pela máquina, com profissionais de outros departamentos.

A maioria usa fones de ouvido para criar e a música varia, dependendo do tipo de 
peça ou campanha: "[...] determinadas músicas me deixam no estado criativo que preciso para escrever esse tipo de linguagem, de texto [...] ou, então, se preciso escrever dez $e$-mails MKT, coloco música eletrônica... que acelera e vamos lá. Quase como se fosse máquina [...]" (REDATOR, agência digital). Há certa desvalorização do próprio trabalho, ao ser comparado a uma máquina de fazer e-mails, naturalizando a pressão por produtividade e eficiência.

Há dois tráfegos na agência, o da criação e o de TI, que executam a organização do fluxo de trabalho, o cronograma, o controle dos recursos e a interface com departamento de Projetos por meio de um sistema "[...] Allocation (parecido com o Google Calendar) para que todos possam visualizar como estão as alocações." (PLANEJAMENTO JR., agência digital, por e-mail).

O acesso ao sistema permitiu ver alguns trabalhos, com apresentações já criadas, e também o encaminhamento das campanhas, até a execução final. Na maioria das vezes, ao assistir às apresentações de planejamento e de criação, notei que pouco diferem, com exceção de ações propostas para ambientes de e-commerce. E, como também acontece na agência tradicional, existem solicitações de clientes que não explicitam necessariamente que tipo de peça/campanha deve ser criada.

[...] quero divulgar um produto novo, pensem pra mim. Então, aqui a gente pode pensar em qualquer coisa pro digital. Então, você vai fazer... a gente sugere que você faça um aplicativo, a gente sugere que você crie um site, a gente sugere faça uma ação nas redes sociais ... ele deixa ... existem muitos briefings abertos. Pode ser que venha um briefing aberto com alguma coisa que ele queira fazer [...] A concorrência está fazendo isso também, quero isso... faz parte do trabalho oferecer outras coisas e avaliar o próprio pedido dele (cliente), mesmo. Às vezes ele pode estar enganado achando que essa é a melhor forma de resolver o problema, mas não é. (DIRETOR DE PROJETOS, agência digital).

Esse posicionamento quanto ao tipo de peça a ser criada, característico de processos midiatizados, altera e é alterado pelos demais processos. Na agência digital, a solicitação é aberta para ideias que possam aflorar do briefing, na resolução de problemas, aproximando os criativos de profissionais de TI, com novos espaços para o programador nas equipes de criação, como observei na agência tradicional (ALVES, 2016). 0 que interessa é a ideia.

[...] qualquer projeto no digital que você tem, acho que a tendência é que dentro da área de criação, de concepção, você começa a envolver outros profissionais de tecnologia também. Até porque, assim, cada vez mais este trabalho é feito em conjunto ou em proximidade, da criação com a tecnologia. Até para você consultar e saber se é possivel, se já foi feito, como a gente viabiliza a ideia, às vezes, assim. Então, dentro do processo de 
criação, acho que está cada vez mais presente o setor de TI, de tecnologia, o programador. Existem programadores que já são programadores criativos ... o cara é diretor de arte, mas gosta de programação [...] (DIRETOR DE ARTE, agência digital).

O planejamento aponta a relevância do departamento de mídia, como também o fez o diretor de criação, seja por meio dos analistas de BI (business intelligence), que conseguem traduzir dados do comportamento do consumidor para orientar novas ações, além da possibilidade de monitoramento e métricas. Trata-se de um dispositivo de controle no polo da recepção: “[...] eu consigo ter, através de tecnologia, uma mescla do que o cara está fazendo na loja, quando ele está com o smartphone dele [...]" (PLANEJAMENTO JR., agência digital). Como aponta Van Dick (2017, p. 47), “[...] as companhias de mídia social monetizam os metadados ao reprocessá-los e vendê-los para anunciantes ou companhias de dados [...]". São esses dados que alimentam as equipes, do planejamento à criação, que se reúnem para traçar caminhos nos quais a mediação humana e a dos meios têm uma relação recíproca, não excludente.

Os processos criativos têm início na compreensão do briefing e do principal problema de comunicação a ser resolvido. Depois, buscam referências na arte, no cotidiano, tendo como principal fonte a internet, onde se atualizam sobre diferentes assuntos, entre eles a própria tecnologia. A midiatização direta e indireta permeia todo o processo criativo, na relação espaço-tempo da contemporaneidade em busca de referências, tantas e tão dispersas que os profissionais criam arquivos pessoais on-line, um vasto arquivo de associações possíveis para ser utilizado no momento certo.

Ao citar o terceiro mapa de Mártin-Barbero, Lopes (2018a) situa a identidade da comunicação, que antes “[...] era achada nos meios e, hoje, ela não se dá somente nos meios. A comunicação ocorre na interação que possibilita a interface de todos os sentidos, portanto, é uma intermediação, que é um conceito para pensar a hibridização das linguagens e dos meios." (LOPES, 2018a, p. 56). Os conceitos criados, porém, nem sempre dão origem a textos verbais e visuais, como vídeos, anúncios ou posts, mas a ações que possam ser publicizadas (CASAQUI, 2011) com ou sem mídia.

0 trabalho solitário é comum, principalmente quando envolve posts criados pelo redator e ilustrados por diretores de arte, similares à prática jornalística na qual matérias são acompanhadas por fotos ou desenhos. Outras vezes, as imagens sugeridas pelos diretores de arte suscitam assuntos, como no caso de posts temáticos. Ao relatar seus processos criativos, o diretor de criação diz trabalhar sozinho, para ter ideias, e depois as 
discute com as equipes. Esse profissional tem passagens por várias agências no Brasil e no mundo e há anos trabalha sozinho, exclusivamente em agências digitais.

\begin{abstract}
Há muitos anos que eu não trabalho em dupla, eu continuo acreditando que a dupla é uma boa unidade de criação, mas já penso em uma dupla alargada, hoje, trabalhando com o digital, penso que a dupla mais alargada, com planejamento e tecnologia [...] Mas meu sistema pessoal de criação é diferente, porque há muito tempo não trabalho em equipe entendeu, é um trabalho individual... tento despachar o dia a dia das coisas [...] E reservo a noite, o início da manhã e a hora do almoço para criar coisas. Como crio? Com caneta BIC e um caderno. Primeiro só a ideia. E muitas vezes divido com a equipe. Chamo a equipe e digo, gente, o que vocês acham dessas ideias? E vamos desenvolver em equipe [...] (DIRETOR DE CRIAÇÃO [redator], agência digital).
\end{abstract}

Escrever ou desenhar as primeiras ideias à mão é uma prática recorrente entre os criativos e os caminhos começam a ser traçados já nas reuniões de briefing. E, apesar de a criação não ter metas a cumprir (como ocorre com o atendimento, por exemplo), há casos em que os jobs são propostos pelo departamento de criação, procedimento desse diretor de criação, que provoca inputs com vistas à renovação da comunicação e maior produtividade.

Uma das campanhas promocionais, em fase de produção nos dias da pesquisa, utiliza personagem e situações de contos de fadas. 0 uso de estereótipos é uma das técnicas de persuasão comuns, só que, nesse caso, foi deslocado para outro contexto, como os readymade analisados por Carrascoza (2008). Segundo o diretor de arte, a imagem da referência do personagem foi encontrada no Google e não em banco de imagens, um meio de fácil acesso a todos. E esse deslocamento teve por objetivo gerar "disrupção" (palavra muito usada pelos publicitários) para manter o consumidor ligado até o "clique aqui" do fim do vídeo, que gera conversão e garante um retorno financeiro maior para a agência.

Falo para o cliente: a gente está há três meses trabalhando com o seu negócio e entendo muito do seu negócio, às vezes até mais do que você, vamos fazer o seguinte ... você paga cinquenta reais por cada conversão que eu trouxer para o teu site. Ele faz as contas e fala, beleza. Só que eu vou trazer 200 mil conversões, você tem dinheiro? Tenho, porque eu vou vender [...] (DIRETOR DE MÍDIA, agência digital).

Parece haver predisposição para um trabalho compartilhado entre os profissionais de criação, de coautoria, somatória de ideias, com créditos divididos no caso de uma campanha de sucesso: "Por que não importa dividir créditos? Porque o trabalho de todo mundo tem de ser bom. Ninguém aqui pode ficar sentado sem fazer nada. Aqui não adianta só uma pessoa fazer, todo mundo tem de fazer." (REDATOR, agência digital). 
Essa integração almejada contrasta com a necessidade de reconhecimento individual, que permite a ascensão profissional. 0 diretor de criação, por exemplo, estava ansioso pelos resultados de uma premiação na qual havia inscrito várias ações; o redator relatou ficar desanimado no mês de junho, quando vê que, novamente, não foi premiado no Cannes Lions, uma das premiações mais cobiçadas por agências e anunciantes. Ou seja, o dito nem sempre é reiterado no dia a dia, como também acompanhei na agência tradicional, apesar da vontade de integração, o trabalho individual é o que tem mais relevância.

\section{Algumas considerações}

A partir das observações realizadas na agência digital foi possível evidenciar um dispositivo tecnocriativo, que leva em conta o controle da mídia e a capacidade de rastrear os consumidores na rede para alimentar as ideias da criação. A lógica algorítmica permite, pela combinação de dados acumulados sobre os consumidores, contar boas histórias para cada perfil comportamental, em caso de campanhas, buscando "disrupção" e experiências com a marca nos meios digitais em suas formas de contato.

[...] na internet você deixa pegadas, você consegue mensurar resultados. Meio que automaticamente você vai migrando o seu investimento onde dá mais retorno, isso é performance. Isso é uma ação diretamente relacionada à venda. Só que ele precisa de um passo anterior de marca. Porque ninguém busca aquilo que não conhece. Ninguém compra aquilo que não conhece. Por mais barato que seja, por melhor que seja a estrutura da campanha [...] (DIRETOR DE MÍDIA, agência digital).

Do mesmo modo que na agência tradicional pesquisada, há midiatização direta e indireta em quase todos os processos e departamentos. Na criação, especificamente, desde as pesquisas de referências, aos modos de fazer e à integração entre departamentos e profissionais, na combinação face a face e mediada. Como exemplo de midiatização indireta, ressalto a maneira pela qual os criativos lidam com as representações do target advindas das narrativas dos media (HJARVARD, 2012, p. 68), uma vez que os qualificam nas escolhas que fazem em pesquisas de referências e os trazem nos mood boards das campanhas, inclusive no exemplo citado, de conto de fadas.

Os fluxos de trabalho são ora lineares ora não, quando há alterações no encaminhamento dos projetos a partir de insights da criação (em vez de começar pelo planejamento). A criação é valorizada e respeitada pelos profissionais de todos os departamentos, por ser a responsável pela magia, como se referiu o diretor de criação. 
Observei, também, certa acomodação dos criativos em relação a procedimentos de trabalho já utilizados, por já terem resultados positivos na conversão de consumidores.

Realizei uma síntese das principais características da agência digital (quadro 1) e o que sinalizam, como os procedimentos semissistêmicos gerenciados por programas informacionais e controlados por dois tráfegos, de projetos e de criação, além de relatórios de timesheet. Porém, algumas vezes, podem ser considerados sistemas pro forma, cujo controle visa simplesmente dimensionar o volume de trabalho, prazos e custos. Ressalto que, nessa agência digital, ficam evidentes os níveis hierárquicos, mas a liderança pode ser compartilhada, uma vez que os fluxos são de fácil controle.

Quadro 1 - Pontos-chave da análise da agência digital

\begin{tabular}{|c|c|}
\hline & Agência digital \\
\hline Hierarquia & oblíqua com liderança compartilhada \\
\hline Orientação & criativa: design + mídia (Big Data) \\
\hline Criação & $\begin{array}{l}\text { em duplas e trincas } \\
\text { direção de criação: redação } \\
\text { gênero masculino menos predominante }\end{array}$ \\
\hline Fluxo & $\begin{array}{l}\text { linear/não linear } \\
\text { simples e rápido }\end{array}$ \\
\hline $\begin{array}{l}\text { Organização e } \\
\text { departamentos }\end{array}$ & $\begin{array}{l}\text { processos integrados: criação predomina, planejamento não valorizado } \\
\text { ascensão da mídia }\end{array}$ \\
\hline Procedimentos & semissistêmicos \\
\hline Palavras-chave & storytelling e comportamento do consumidor: eficiência \\
\hline Relação com o consumidor & midiatização direta e indireta: conversão \\
\hline Publicidade é & $\begin{array}{l}\text { criatividade e engajamento: } \\
\text { "olha o que a minha marca tem a dizer a você" }\end{array}$ \\
\hline
\end{tabular}

Fonte: Elaborado pela autora.

As ações do consumidor nas mídias digitais e nas redes on-line têm promovido uma reação das agências, de diferentes modelos, para ampliar a prestação de serviços de comunicação por meio da tecnologia, o que requer aproximar sistemas informacionais e inovações técnicas da criação de campanhas, permeadas por ações que visam a interação com o consumidor.

Neste texto pude trazer algumas observações e análises da agência digital pesquisada, na qual o movimento por interação está na origem, intensificado com o domínio mais técnico da programação e do comportamento do consumidor, em um mundo cada vez 
mais dataficado, cujo controle me pareceu naturalizado, inclusive dos próprios processos de trabalho e dos trabalhadores.

\section{Referências}

ACCENTURE Interactive anuncia aquisição da Droga5. São Paulo: PROPMARK: 2019.

ASSOCIAÇÃO BRASILEIRA DOS AGENTES DIGITAIS. Valores referenciais de serviços internos. São Paulo: ABRADI, 2020. Disponível em: http://conteudo.abradi.com.br/guia-vrabradi-sp. Acesso em: set. 2021.

ALVES, M. C. D. Mediações e os dispositivos dos processos criativos da publicidade midiatizada: vestígios e perspectivas. Tese (Doutorado em Ciências da Comunicação), Escola de Comunicações e Artes da Universidade de São Paulo, p. 227, 2016.

AGAMBEN, G. ¿Qué es un dispositivo? Sociológica, Ciudad de México, v. 26, n. 73, p. 249264, 2011.

BARROS, L. M. Recepção, mediação e midiatização: conexões entre teorias europeias e latino-americanas. In: MATTOS, M. et al. (org.) Mediação \& midiatização. Salvador: EDUFBA, 2012.

BRAGA, J. L. A sociedade enfrenta a sua mídia: dispositivos sociais de crítica midiática. São Paulo: Paulus, 2006.

BRAGA, J. L. Midiatização: a complexidade de um novo processo social. Revista do Instituto Humanitas Unisinos, São Leopoldo, n. 289, 2009.

BRAGA, J. L. Interação como contexto da Comunicação. MATRIZes, São Paulo, v. 6, n.1, 2012.

CARRASCOZA, J. A. A evolução do texto publicitário. São Paulo: Futura, 1999.

CARRASCOZA, J. A. Redação publicitária: estudos sobre a retórica do consumo. São Paulo: Futura, 2003.

CARRASCOZA, J. A. Do caos à criação publicitária: processo criativo, plágio e ready-made na publicidade. São Paulo: Saraiva, 2008.

DELEUZE, G. Que és un dispositivo? In: BALIBAR, E.; DREYFUS, H.; DELEUZE, G. et al. Michel Foucault, filósofo. Barcelona: Gedisa, 1999.

FAUSTO NETO, A. As bordas da circulação. Revista ALCEU, Rio de Janeiro, v. 10, n. 20, 2010.

FOUCAULT, M. Microfísica do poder. Rio de Janeiro: Graal, 2000.

HEPP, A. Deep Mediatization. New York: Routledge, 2020. 
HJARVARD, S. Midiatização: teorizando a mídia como agente de mudança social e cultural. MATRIZes, São Paulo, v. 5, n. 2, 2012.

LOPES. M. I. V. Mediação e recepção. Algumas conexões teóricas e metodológicas nos estudos latino-americanos de comunicação. MATRIZes, São Paulo; v. 8, n. 1, 2014.

LOPES. M. I. V. Jesús Martín-Barbero e os mapas essenciais para compreender a comunicação. Intexto, Porto Alegre, n. 43, 2018.

LOPES. M. I. V. A teoria barberiana da comunicação. MATRIZes, São Paulo, v. 12, n. 1, $2018 a$.

MARTÍN-BARBERO, J. Uma aventura epistemológica. MATRIZes, São Paulo, v. 2, n. 2, 2009.

PERUZZO, M. C. K. Da observação participante à pesquisa-ação em comunicação:

pressupostos epistemológicos e metodológicos. In: Congresso Brasileiro de Ciências da Comunicação, 26., 2003, Belo Horizonte. Anais [...]. São Paulo: Intercom, 2003.

PIENIZ, M. B.; CENCI, M. P. Tecnicidades de las mediaciones comunicativas de la cultura a las mutaciones culturales. In: JACKS, N.; SCHMITZ, D.; WOTTRICH, L. (org.) Un nuevo mapa para investigar la mutación cultural: diálogo con la propuesta de Jesús Martín-Barbero. Quito: Ediciones CIESPAL, 2019.

PINHO, J. B. Publicidade e vendas na internet: técnicas e estratégias. São Paulo: Summus, 2000.

TRINDADE, E. Estudos mediáticos da publicidade e seu capital simbólico. In: Congresso Brasileiro de Ciências da Comunicação da Região Sudeste, 12., 2007, Juiz de Fora. Anais [...]. São Paulo: Intercom, 2007.

VAN DICK, J. Confiamos nos dados? As implicações da datificação para o monitoramento social. MATRIZes, São Paulo, v. 11, n. 1, 2017.

VERÓN, E. Teoria da midiatização: uma perspectiva semioantropológica e algumas de suas consequências. MATRIZes, São Paulo, v. 8, n. 1, 2014.

\title{
Between people and processes: observations on a Brazilian digital advertising agency
}

\begin{abstract}
The work of advertising agencies has changed in recent years, whether it's the business model itself or the flow and procedures. In my ethnographic research, I observed some of these changes across three Brazilian agencies models: traditional, digital and collaborative. Specifically, in this text, I bring an excerpt of research in a digital agency and the main analyzes carried out from a theoretical framework that covers the concepts of dispositif, mediation and mediatization. During
\end{abstract}


the research, it was possible to observe the interaction, technical knowledge aligned with the media, and creative processes valued for the ability bring ideas to life. There is a reaction from agencies to expand the provision of communication services through technology, which requires bringing information systems and technical innovations closer to the creation of campaigns. In the researched digital agency, the interaction is at its origin, intensified by technical domain of programming and consumer behavior, in an increasingly data driven world.

\section{Keywords}

Digital ad agency; Dispositif; Interaction; Mediation; Mediatization

\section{Autoria para correspondência}

Maria Cristina Dias Alves

crisdays@gmail.com

\section{Como citar}

ALVES, Maria Cristina Dias. Entre pessoas e processos: observações sobre uma agência de publicidade digital. Intexto, Porto Alegre, n. 52, e-105670, jan./dez. 2021.

DOI: http://dx.doi.org/10.19132/1807-8583202152.105670

Recebido em 24/07/2020

Aceito em 19/06/2021 